\title{
Diacerein, its beneficial impact on chondrocytes and notable new clinical applications
}

\author{
Daljit Kaur, Jaspreet Kaur ${ }^{1 *}$, Sukhmeet Singh Kamal ${ }^{1}$
}

${ }^{1}$ Rayat-Bahra Institute of Pharmacy, Hoshiarpur, India

\begin{abstract}
Diacerein (DCN) was obtained by diacetylation of an anthraquinone derivative rhein and was approved by FDA in 2008, in the treatment of osteoarthritis due to its inhibitory effect on proinflammatory cytokines, including IL-6 and IL-1 $\beta$. It was synthesized in 1980s and marketed as a tablet in some European Union and Asian countries from 1994. Along with its great potential in the treatment of osteoarthritis, its other applications are also being explored day by day, such as in the treatment of psoriasis, epidermolysis bullosa, breast cancer, type 2 diabetes and periodontitis. The main aim of this review is to explore mechanism of action, various applications and side effects associated with DCN. This has been reviewed that apart from the risk of diarrhea on long-term administration of DCN, various clinical studies has also shown its modest benefits in treatment of various pathological conditions. Hence, DCN is emerging as a new and potentially safe derivative with maximum therapeutic efficacies and minimum side effects which can results in improving the living status of patients suffering from various inflammatory diseases.
\end{abstract}

Keywords: Diacerein/osteoarthritis. Drug/chondroprotective. Diacerein/mechanism of action. Drug/ adverse effects. Diacerein/contraindications.

\section{INTRODUCTION}

DCN is emerging as a new chondroprotective agent used widely for symptomatic treatment of osteoarthritis (OA) i.e. degradation of joint cartilage and underlying bone as it prevents cartilage breakdown and slows down the progression of cartilage lesions (Pelletier et al., 2001; Jatwa, Kar, 2009). Several animal model studies and clinical trials have been conducted which demonstrated great role of DCN in the protection of cartilage matrix and symptomatic improvement among patients suffering from this degenerative disease, respectively (Pelletier et al., 2001). Dogs, sheep, guinea pig and rabbits were used in animal models (Pelletier et al., 2000). Several rheumatology societies have introduced DCN in their therapeutic guidelines as a treatment option in OA such as the European League Against Rheumatism (EULAR) and the Osteoarthritis Research Society International (OARSI) (Pavelka et al., 2016). DCN belongs to the class of anthraquinone derivatives found in Cassia gender plant, which has anti-inflammatory, analgesic and antipyretic

\footnotetext{
*Correspondence: Jaspreet Kaur. Assistant Professor, Rayat-Bahra Institute of Pharmacy, Hoshiarpur, India. Phone: 09888992337. E-mail: jaspreet.meehnian@gmail.com
}

activity (Magnard et al., 1993; Cardoso et al., 2017). In the International Union of Pure and Applied Chemistry, it is named as 4,5-diacetyloxy-9,10-dioxo-anthracene2-carboxylic acid (Elena, Newman, Gumus, 2009). DCN reduces the concentration of pro-inflammatory cytokines due to which it also has protective effect on granuloma induced cartilage breakdown. DCN belongs to BCS class II with poor aqueous solubility of 3.197 $\mathrm{mg} / \mathrm{mL}$ due to which only $35-56 \%$ of drug reaches the systemic circulations (Parekh, Paun, Soniwala, 2017). Both DCN and its active metabolite, rhein are considered powerful inhibitors of cytokines synthesis (IL-1 $\beta$ ) and metalloproteases (collagenase and stromelysin) which are main inflammatory mediators involved in cartilage breakdown (Pelletier et al., 2000). DCN come under disease modifying osteoarthritis drugs (DMOADs), which reduces the severity of disease and restrains the progression rate of degraded cartilage. DCN also upregulates the expression of transforming growth factors (TGF- $\beta 1$ and TGF- $\beta 2$ ), even in the absence of IL-1 $\beta$. Along with this it also antagonizes the IL-1 $\beta$ triggered mitogen-activated protein kinase signaling cascades of articular chondrocytes and stimulates cartilage regeneration process (Frohnwiesery et al., 2014). In March 2014, the European Medicines Agency (EMA) conducted 
a review on the request of French medicines agency, which was mainly concerned with frequency and severity of diarrhea and liver disorders in OA patients. The EMA's Pharmacovigilance Risk Assessment Committee (PRAC) questioned the limited clinical benefits associated with DCN, which did not outweigh its risks and they restricted the use of DCN containing medicines for patients aged $\geq 65$. In order to minimize these risks, this was advised that patients should start treatment on half of the normal dose (i.e. $50 \mathrm{mg}$ /day instead of $100 \mathrm{mg} /$ day) for first 2-4 weeks and should stop taking DCN on account of diarrhea (Panova, Jones, 2015; Pavelka et al., 2016). The Pharmacovigilance Risk Assessment Committee of European Medicines Agency, the European Society for Clinical and Economic Aspects of Osteoporosis and Osteoarthritis (ESCEO) confirmed that after first month of treatment with DCN and non-steroidal anti-inflammatory drugs (NSAIDs), the resulted efficacy was same but superior to that of Paracetamol. For patients in whom NSAIDs or Paracetamol are contraindicated, ESCEO has recommended DCN as first line therapy in the treatment of OA. Based on these evidences ESCEO concluded that the benefit-risk balance of DCN remains positive in the symptomatic treatment of hip and knee OA (Pavelka et al., 2016). In 2015, a study was conducted in which efficacy of DCN was found to be maximum as compared to Diclofenac sodium in OA induced albino rats (Osman et al., 2015). Diacerein is a slow acting drug, whose response is attained gradually (4-6 weeks), but after withdrawal, its symptomatic effect persists for several months (4-8 weeks) (Medhi et al., 2007; Akhter et al., 2015).

\section{DIACEREIN AS A POTENTIAL SALVAGER OF CHONDROCYTES IN OSTEOARTHRITIS}

Osteoarthritis is derived from Greek words "Osteon" meaning the bone, "arthon" meaning joint and the suffix "itis" means inflammation (Aigner, Schmitz, 2011). This chronic disease is most common form of arthritis among older adults, also known as degenerative arthritis or osteoarthrosis. A degenerative disease is generally considered as a clinical syndrome in which low grade inflammation results in painful joints (Woolf, Pfleger, 2003). It affects about $9.6 \%$ men and $18 \%$ women, aged $>60$ years, post-menopausal women are more susceptible to OA as compared to men of the same age group (Woolf, Pfleger, 2003; Tanamas et al., 2011). This musculoskeletal disease is considered as a main cause of chronic disability in USA and has been expected as fourth leading cause of disability by the year 2020 (Woolf, Pfleger, 2003).

OA can affect any joint of human body, but it occurs most often in knees, hips, lower back, neck, small joints of the fingers, bases of the thumb and big toe. With each decade of life the prevalence of symptomatic knee OA increases, as its annual incidences being highest between 55 and 64 years old. In 2010, the prevalence of symptomatic knee OA in patients aged $\geq 45$ had been estimated between $5.9 \%$ to $13.5 \%$ in men and $7.2 \%$ to $18.7 \%$ in women, whereas approximately 10 million adults had symptomatic knee OA. As the world's population continues to age, it is estimated that degenerative joint disease disorders such as OA will impact at least 130 million individuals around the globe by the year 2050 (Arthritis Foundation, 2017). Treatment options for OA are an actual challenge due to the poor selfhealing capacity of cartilage (Frohnwieser et al., 2017). The most effective class of drugs for the symptomatic relief in severe cases of OA is NSAIDs. Although NSAIDs have lower chances of gastric irritation but long-term use could increase the chance of cardiovascular disease (Flood, 2010). Oral steroids and some rubefacients such as capsaicin and intra-articular hyaluronan injections are also used for the treatment of OA. Despite of their modest benefits they are not recommended because of their high rate of side effects (Chen et al., 2008).<smiles>CC(=O)Oc1cccc2c1C(=O)c1c(OC(C)=O)cc(C(=O)O)cc1C2=O</smiles>

Diacerein (Molecular weight $=368)$

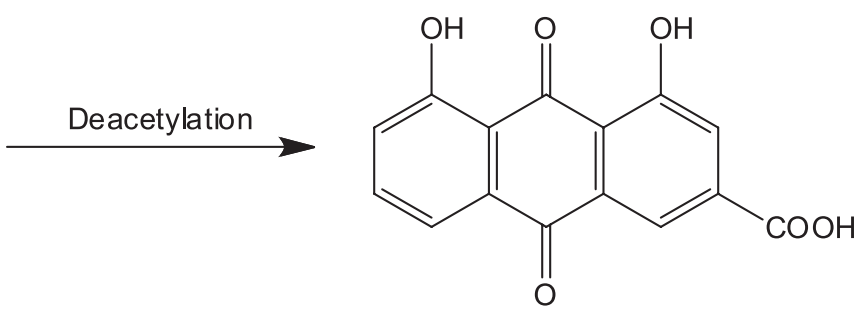

Rhein $($ Molecular weight $=284)$

FIGURE 1 - Metabolism of DCN. 
So, development of effective alternatives to NSAIDs is the need of the hour due to which new drug molecules are emerging. DCN, glucosamine sulfate, glucosamine hydrochloride, chondroitin sulfate, hyaluronic acid and avocado soybean unsaponifiables (ASU) are second line drugs for the treatment of OA which are classified as symptomatic slow acting drugs (SYSADOA). As compared to NSAIDs and placebo, DCN is effective in the symptomatic OA as well as any structural changes occurring in OA of the knee (Kongtharvonskul et al., 2015), hence EULAR has recommended DCN as IL-1 $\beta$ inhibitor, in its guidelines in 2003. Previous systematic reviews on DCN have showed its higher efficacy in reducing the pain and Lequesne index but increased risk of diarrhea as compared to placebo (Rintelen, Neumann, Leeb, 2006; Bartels et al., 2010). From 1982 several trials have been conducted on DCN to evaluate its efficacy and severity in the treatment of OA and since 1984 DCN has been marketed all over the world, with exception in USA (Fidelix et al., 2014).

DCN is different from the conventional NSAIDs due to the following two reasons:

- It prevents the loss of hydroxiproline and proteoglycans present in the joint cartilage by stimulating the production of TGF- $\beta$ (Mahajan et al., 2006; Medhi et al., 2007).

- $\quad$ DCN does not have any inhibitory effect on phospholipase- $\mathrm{A}_{2}\left(\mathrm{PLA}_{2}\right)$, cyclooxygenase (COX), lipoxygenase (LOX) and prostaglandins (PGs) synthesis due to which it does not cause any gastro-duodenal toxicity (Pelletieret al., 1998; Zaki et al., 2013).

\section{MECHANISM OF ACTION}

IL- $1 \beta$ is a biologically inactive precursor which is synthesized in the cell. To exit from the cell, it requires proteolytic cleavage which further allows the activation of cytokine. IL-1-converting enzyme (ICE) also known as caspase-1, which is an endopeptidase localized intracellularly, completes the above stated process. The level of ICE gets elevated in OA due to which the secretion as well as activity of the cytokine gets increased. Hence, DCN reduces the level of ICE which results in inhibition of IL-1 $\beta$ (Moldovan et al., 2000; Pelletier, Pelletier, 2010). In case of human OA chondrocytes, IL-1 promotes the expression of inducible nitric oxide synthase, enhances the release of $\mathrm{PGE}_{2}$ and stimulates matrix metalloproteinases (MMPs) which results in joint degradation (Rao et al., 2009). The levels of collagenase and stormelysin get increased in the synovial fluid due to activation of MMPs which results in cartilage destruction (Yaron, Shirazi,
Yaron, 1999). IL-1 activates monocytes/macrophages which results in inflammation, by inducing fibroblasts proliferation it causes synovial pannus formation, breakdown of cartilages by activation of chondrocytes and bone resorption by activation of osteoclasts (Mahajan et al., 2006).

DCN improves various pathological conditions that are responsible for $\mathrm{OA}$ by following mechanisms:

i. By selective inhibition of IL-1, DCN improves all the pathological conditions responsible for joint degeneration in human volunteers experiencing the OA of finger joint and knee. DCN also inhibits the IL-1 induced expression of enzymes which are responsible for the destruction of cartilage (Mahajan et al., 2006; Felisaz et al., 1999).

ii. Nuclear factor kappa B (NF- $\kappa \mathrm{B})$ and activator protein-1 (AP-1) are transcription factors responsible for the expression of several pro-inflammatory genes by chondrocytes, DCN retards the binding of these transcription factors (Leeb, 2010).

iii. As it has a property of disease modifying agent therefore DCN improves the expression of TGF- $\beta 1$ and TGF- $\beta 2$ which favours the conditions such as matrix synthesis and turnover in articular chondrocytes. DCN reduces the turnover of chondroitin4-sulphate, which causes great decrease in the ratio of chondroitin-6-sulphate to chondroitin-4-sulphate. By this mechanism DCN can protect the proteoglycan aggrecan which is composed of chondroitin sulphate and keratin sulphate chains ultimately helpful in allowing articular cartilage to resist compression under load (Medhi et al., 2007).

iv. Drug is a potent and selective inhibitor of $N$-acylethanolamine-hydrolyzing acid amidase (NAAA), which catalyzes the hydrolysis of palmitoylethanolamide (PEA). PEA is a protective endogeneous mediator, gets stimulated during inflammatory and neurodegenrative conditions to exert an antiinflammatory as well as analgesic action. PEA also acts by down regulating the mast cell degradation through an Autocoid Local Inflammation Antagonism (ALIA) mechanism (Petrosinoet al., 2014).

v. DCN also retards the superoxide production, chemotaxis and phagocytic activity of neutrophils by having an additional effect on macrophages migration and phagocytosis. DCN also reduces the number of urokinase receptors on chondrocytes upto normal level and reduces the fibrinolytic activity in synovial fluid (Pelletier et al., 2000; Mahajan et al., 2006). 


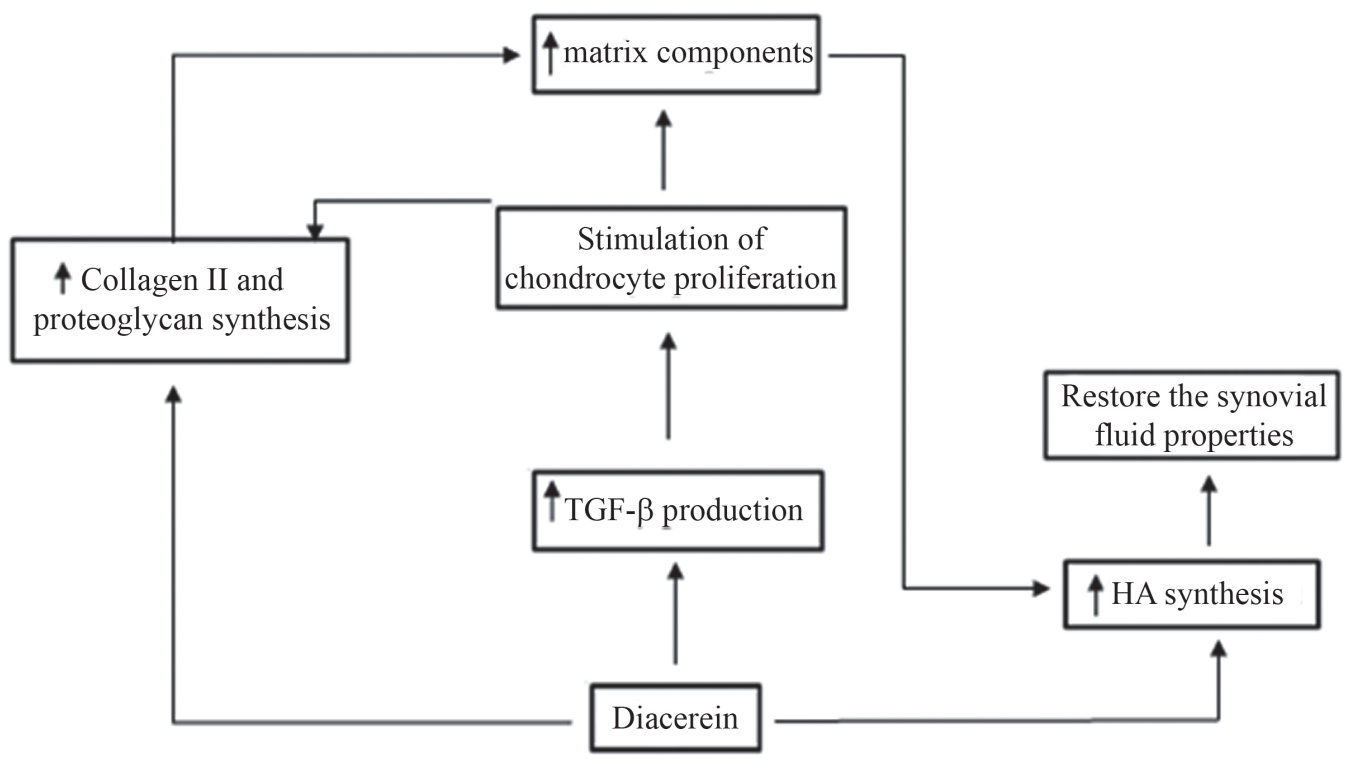

FIGURE 2- Anabolic effect of DCN (Medhi et al., 2007).

vi. DCN shows inhibitory effect on production of collagenases and also promotes the synthesis of proteoglycans which are inhibited by IL-1 (Felisaz et al., 1999).

\section{METABOLISM AND ELIMINATION}

After oral administration of $50 \mathrm{mg}$ dose of DCN, $19.6 \pm 11.3 \%$ of its non-conjugated metabolite gets excreted in the urine while $62.7 \pm 13.5 \%$ was in the form of glucuroconjugated rhein and $18.6 \pm 5.6 \%$ in the form of sulphuronoconjugated rhein (Louchahi, Nicolas, Petitjean, 1991; Mahajan et al., 2006; Medhi et al., 2007).

TABLE I - Urinary excretion pharmacokinetic parameters of DCN after oral administration (Medhi et al., 2007)

\begin{tabular}{lc}
\hline Parameter & $\begin{array}{c}\text { Estimated } \\
\text { value }\end{array}$ \\
\hline $\begin{array}{l}\text { Apparent availability of rhien by urinary } \\
\text { data assessment }\end{array}$ & $35 \%$ \\
$\begin{array}{l}\text { Maximum plasma concentration }\left(\mathrm{C}_{\mathrm{max}}\right), \\
\text { after } 2.2 \mathrm{hrs}\end{array}$ & $3.2 \mathrm{~mm} / \mathrm{L}$ \\
$\begin{array}{l}\text { Area under the plasma concentration-time } \\
\text { curve }\left(\mathrm{AUC}_{\mathrm{o}}\right)\end{array}$ & $21.3 \mathrm{mg} / \mathrm{L} / \mathrm{h}$ \\
Apparent volume of distribution $\left(\mathrm{V}_{\mathrm{d}}\right)$ & $13.2 \mathrm{~L}$ \\
Apparent total plasma clearance $\left(\mathrm{CL}_{\mathrm{t}}\right)$ & $1.6 \mathrm{~L} / \mathrm{h}$ \\
Renal clearance $\left(\mathrm{CL}_{\mathrm{r}}\right)$ & $0.13 \mathrm{~L} / \mathrm{h}$ \\
Elielimination half life $\left(\mathrm{t}_{1 / 2}\right)$ & $4.3 \mathrm{~h}$ \\
\hline
\end{tabular}

\section{PHARMACOLOGICAL USE OF DIACEREIN IN VARIOUS PATHOLOGICAL CONDITIONS OTHER THAN OSTEOARTHRITIS}

Jatwa and Kar (2009), provided an evident study, according to which various adverse effects (such as irritant induced altered glucose levels and lipid metabolism, oxidative stress and decreased levels of thyroid hormones) were found to be reversed in carrageenan treated animals on administration of DCN for 21 days.

Ramos-Zavala et al. (2011), had reported increased insulin secretion in patients who were on DCN therapy, reason being is inhibition of both cytokines IL- $1 \beta$ and TNF- $\alpha$, which plays an important role in the apoptosis of $\beta$-cell.

Recently, a randomized clinical trial has been conducted according to which DCN reduced the mean $\mathrm{HbA}_{1 \mathrm{c}}$ levels, with peak effect at the 24 th week of treatment. The drug was well tolerated and might be indicated as adjunct treatment of patients with type 2 diabetes, particularly in those with OA (Cardoso et al., 2017). As a low-grade chronic inflammatory state was observed in obesity and type 2 diabetes. In type 2 diabetes, a great decrease in insulin secretion has been observed due to presence of some pro-inflammatory cytokines (TNF$\alpha$, IL-1 $\beta$ and IL-6), which causes apoptosis of $\beta$ cells. In previous studies, activity of DCN had been studied in various animal models of obesity and diabetes, which demonstrated down regulation of these pro- inflammatory cytokine expression, which resulted in improved glucose tolerance and lower fasting glycemia levels (Cardoso et al., 2017; Villar et al., 2017). 
Kumar et al. (2011), prepared the DCN cream which was found to be effective in the treatment of psoraisis in those patients who did not respond to other medicines.

Mohan et al. (2017), explained the role of DCN in psoriasis, as psoriasis has increased IL-1 activity which also increased the risk of atherosclerosis and cardiovascular morbidity. DCN reverses the proatherogenic and pro-inflammatory gene regulation caused by IL-1 in endothelial cells and keratinocytes, potentially preventing progression of skin inflammation and inflammation induced atherosclerosis.

Torina et al., (2015) investigated the effect of DCN on ventricular remodeling. The study estimated that treatment with DCN once a day for 4 weeks after myocardial infarction improved ventricular remodeling by promoting lower end-systolic and end-diastolic left ventricular volumes. DCN also reduced the fibrosis in the left ventricular, as DCN was associated with partial blockage of the NF- $\kappa$ B pathway.

Along with chondroprotective activity, DCN $\alpha$-aminophosphonate conjugate has been reported to have anti-proliferative activities on tumor cells. A study was conducted, which revealed for the first time that DCN decreases the viability of human chondrosarcoma cells and induces $\mathrm{G} 2 / \mathrm{M}$ cell cycle arrest, in dose dependent manner, by down-regulation of CDK1/cyclin B1 (Lohberger et al., 2015). In 2015, in vivo antitumor potential of DCN for 28 days in dose dependent manner was conducted in MDAMB-231 xenograft model, which demonstrated that DCN caused dose-dependent anti-proliferative effect on breast cancer cells MCF-7, MDA-MB-231, MDA-MB-468 and T47D. The current study presented that targeted inhibition of IL-6/IL-6R-mediated STAT3, MAPK and Akt signaling by DCN, provides new therapeutic regimens for breast cancer. As high level of IL-6 presents in tumor microenvironments which promotes several oncogenic signaling (Bharti et al., 2016).

In 2013, a randomized controlled pilot study was conducted, in which DCN showed positive results against epidermolysis bullosa within 2 weeks (Wally et al., 2013).

DCN is considered as effective in the treatment of periodontal disease because of inhibition of the release of various inflammatory mediators like pro-inflammatory cytokines (IL-1, IL-6, TNF- $\alpha$ ), lytic enzymes like matrix metalloproteinases (MMPs) and prostaglandins (PG). Efficacy of DCN in periodontitis has been evaluated by using rats and results showed great decrease in IL-1 $\beta$ level from baseline to two weeks as well as from baseline to four weeks (Zaki, Aly, Mahmoud, 2015). Recently a study was conducted by Enji et al. (2016), which revealed great decrease in the levels of IL-1 and osteocalcin in gingival crevicular fluid (GCF) of the patients ( 45 subjects divided into three groups) suffering from chronic periodontitis.

\section{EXPLORED ADVERSE EFFECTS OF DIACEREIN}

As rhein is an active metabolite of DCN and due to presence of anthraquinone ring in rhein it has antiinflammatory, hepatoprotective, nephroprotective, chondroprotective, antioxidant, anticancer, antidiabetic, antimicrobial, purgative and lipid lowering pharmacological activities (Yan et al., 2015). Despite of these pharmacological activities, its incomplete absorption in the gut causes undesirable side effects such as laxative action, diarrhea and abdominal pain (Dubey et al., 2009). Long term administration causes undesirable side effects due to accumulation of DCN and rhein. When rhein reaches the colonic site, it gets converted into the rhein-9-anthrone which is particularly responsible for the soft stools (Nakhat et al., 2015). On $100 \mathrm{mg}$ of oral administration of DCN daily, $46 \%$ patients had been reported the incidence of diarrhea (Mandawgade et al., 2016).

The incomplete absorption of DCN from gut produces diarrhea by various mechanisms such as:

Intake of DCN causes the inhibition of IL- $1 \beta$ which could be directly related to diarrhea. Kruse et al., (2008), provided a clinical evidence of increased concentration of IL-1 $\beta$ at the beginning of dysentery in pigs and Escherichia coli induced diarrhea. Any infection in the gut triggers the immune system which causes the release of cytokine and TNF- $\alpha$ as a part of immune system. Hence, the DCN receiving patients became less susceptible to fight against any infection related to gut, due to which incidence of diarrhea increases in such group of patients as DCN directly inhibits the IL- $1 \beta$ which is present in the gut (Gwee et al., 2003; Kruse et al., 2008; Bartels et al., 2010). Another major cause of diarrhea is the capability of DCN to induce prostaglandin synthesis such as $\mathrm{PGE}_{2}$ which increases the amount of gut fluid due to which the motility of the gut increased (Pelletier et al., 2000; Gupta, Datta, 2012).

Other major adverse effect associated with DCN is the reactivation of tuberculosis in patients receiving DCN. As TNF- $\alpha$ and IL-1 has played an important role in the constitution of granulomas and immune protection during the early phase of granulomatous infection like TB. Several in vitro studies demonstrated that apart from IL-1 inhibition, DCN also inhibits other interleukins such as IL-2 and IL-12 which decreases the body's resistance to tubercle bacilli especially during the first 2 months of infection. IL-12 inhibition has significantly decreased the lytic activity of polymorphoneuclear leukocytes and 
mononuclear cells against $M$. tuberculosis infected cells (Gupta, Datta, 2012).

TABLE II - Uses and adverse effects of DCN

\begin{tabular}{|c|c|c|}
\hline Uses of DCN & $\begin{array}{c}\text { Adverse effects of } \\
\text { DCN }\end{array}$ & Reference \\
\hline $\begin{array}{l}\text { Osteoarthritis } \\
\text { Coxathrosis } \\
\text { Gonarthrosis }\end{array}$ & Diarrhea & $\begin{array}{c}\text { Shafshak et al., } \\
\text { 2012; Bruyere et al. } \\
2008\end{array}$ \\
\hline $\begin{array}{l}\text { Rheumatoid } \\
\text { arthritis }\end{array}$ & $\begin{array}{l}\text { Intense yellow } \\
\text { coloured urine }\end{array}$ & $\begin{array}{c}\text { Shafshak et al., } \\
2012\end{array}$ \\
\hline Psoriasis & Stomach pain & $\begin{array}{l}\text { Napoli, 2003; } \\
\text { Shafshak et al., } \\
2012\end{array}$ \\
\hline $\begin{array}{l}\text { Epidermolysis } \\
\text { bullosa }\end{array}$ & $\begin{array}{l}\text { Nausea and } \\
\text { vomiting }\end{array}$ & $\begin{array}{l}\text { Wally et al., 2013; } \\
\text { Shafshak et al., } \\
2012\end{array}$ \\
\hline Periodontitis & Heartburn & $\begin{array}{l}\text { Zaki, Mahmoud, } \\
\text { Aly, 2015; Shafshak } \\
\text { et al., } 2012\end{array}$ \\
\hline
\end{tabular}

\section{CONTRAINDICATIONS}

Daily dose of DCN should be reduced to half for patients having severe kidney failure and creatinine clearance less than $30 \mathrm{ml} / \mathrm{min}$.

DCN is contraindicated in following conditions:

- $\quad$ Severe liver failure (Art50-DL, 2012; Artrodar ${ }^{\circledR}$, CMDh, 2014)

- Inflammatory organic bowel disease such as ulcerative colitis and crohn's disease

- Intestinal or partial obstruction

- Abdominal pain syndromes of indeterminate etiology

- Episodes of hypersensitivity to rhein or other anthraquinine derivatives

\section{SPECIAL WARNINGS AND PRECAUTIONS FOR USE}

DCN should not be recommended during pregnancy, lactation and to children under age of 15 years. DCN capsules must not be administered in case of congenital galactosemia, glucose or galactose malabsorption syndrome or lactase deficiency because of the presence of lactose. DCN should not be recommended to patients already receiving ACE inhibitors or diuretics as there is an increased risk of salt, water depletion which may lead to dehydration and hypokalaemia as DCN causes diarrhea (Art50-DL, 2012).

\section{DRUG INTERACTIONS}

TABLE III - Interaction of DCN with other drugs

\begin{tabular}{|c|c|c|}
\hline Interaction with & Inference & Reference \\
\hline $\begin{array}{l}\text { Antacids } \\
\text { (aluminium, } \\
\text { calcium and } \\
\text { magnesium } \\
\text { salts, oxides or } \\
\text { hydroxides) }\end{array}$ & $\begin{array}{c}\text { Decreased } \\
\text { digestive } \\
\text { absorption of } \\
\text { DCN. Hence, } \\
\text { antacids should } \\
\text { be taken with the } \\
\text { interval of } 2 \text { hours } \\
\text { from DCN, if } \\
\text { necessary }\end{array}$ & Art50-DL, 2012 \\
\hline $\begin{array}{l}\text { Excess fibres or } \\
\text { phytates }\end{array}$ & $\begin{array}{c}\text { Modified } \\
\text { intestinal transit } \\
\text { or the quality of } \\
\text { intestinal content }\end{array}$ & $\begin{array}{c}\text { Artrodar }{ }^{\circledR} \text { CMDh, } \\
2014\end{array}$ \\
\hline $\begin{array}{l}\text { Antibiotics or } \\
\text { chemotherapy }\end{array}$ & $\begin{array}{c}\text { Increased } \\
\text { enterocolic events }\end{array}$ & $\begin{array}{c}\text { Artrodar }{ }^{\circledR} \text { CMDh, } \\
2014\end{array}$ \\
\hline $\begin{array}{l}\text { Diuretics } \\
\text { (high ceiling } \\
\text { loop diuretics } \\
\text { and thiazides) } \\
\text { andcardiac } \\
\text { glycosides } \\
\text { (digitoxin, } \\
\text { digoxin) }\end{array}$ & $\begin{array}{l}\text { Increased risk of } \\
\text { arrhythmias }\end{array}$ & WHO, 2014 \\
\hline
\end{tabular}

\section{CONCLUSION}

DCN is emerging as a new alternative to NSAIDs as it does not have any effect on COX-II and hence no gastric irritation. Along with its effective use in the treatment of OA, DCN is a potential molecule in the treatment of psoraisis, epidermolysis bullosa, rheumatoid arthritis and periodontitis. The main toxicity caused by DCN is mild to moderate diarrhea, of which there is an increasing risk with increasing dose and duration. Further research is needed for effective delivery of DCN in OA because when it is administered at dose 100-150 mg daily, the concentration of drug that reaches the synovial fluid ranges from $10^{-7}$ to $10^{-4} \mathrm{M}$. As very low concentration of drug reaches to synovial fluid, this leads to its slow onset of action (about 3 months) after the start of therapy.

From this extensive review it has been concluded that DCN is a potential drug molecule and it is imperative to apply various pharmaceutical techniques to develop a robust dosage form with effective drug delivery at low possible dose without any side effect. 


\section{REFERENCES}

Aigner T, Schmitz N. Pathogenesis and pathology of osteoarthritis. In: Hochberg M, Silman A, Smolen J, Weinblatt M, Weisman M (editors). Rheumatology. 5th ed. Philadelphia: Mosby Elsevier; 2011. 1741-59 p.

Akhter N, Khan AA, Ayaz SB, Akhter SMH, Afzal A. Diacerein: A treatment option in painful primary knee osteoarthritis. Pak Armed Forces Med J. 2015;65(1):77-80.

Arthritis Foundation. Arthritis by the numbers. Book of trusted facts and figures. Section-2. Arthritis Foundation. 2017;1.2:9-15.

Artrodar ${ }^{\circledR}$ (diacerein) $50 \mathrm{mg}$ capsules. Under License: TRB Chemedica International, Geneva, Switzerland. Highnoon Laboratoeries Ltd.; 2014.

Bartels EM, Bliddal H, Schondorff PK, Altman RD, Zhang W, Christenseny R. Symptomatic efficacy and safety of diacerein in the treatment of osteoarthritis: A meta-analysis of randomized placebo-controlled trials. Osteoarthritis Cartilage. 2010;18(3):289-96.

Bharti R, Dey G, Ojha PK, Rajput S, Jaganathan SK, Sen R, Mandal M. Diacerein-mediated inhibition of IL-6/IL-6R signaling induces apoptotic effects on breast cancer. Oncogene. 2016;35(30):3965-75.

Bruyere O, Burlet N, Delmas PD, Rizzoli R, Cooper C, Reginster JY. Evaluation of symptomatic slow-acting drugs in osteoarthritis using the GRADE system. BMC Musculoskeletal Disorders. 2008;9:1-9.

Cardoso CRL, Leite NC, Carlos FO, Loureiro AA, Viegas BB, Salles GF. Efficacy and safety of diacerein in patients with inadequately controlled type 2 diabetes: a randomized controlled trial. Diabetes Care. 2017;40(10):1356-63.

Chen YF, Jobanputra P, Barton P, Bryan S, Fry-Smith A, Harris G, Taylor RS. Cyclooxygenase-2 selective non-steroidal antiinflammatory drugs (etodolac, meloxicam, celecoxib, rofecoxib, etoricoxib, valdecoxib and lumiracoxib) for osteoarthritis and rheumatoid arthritis: A systematic review and economic evaluation. Health Technol Assess. 2008;12(11):1-278.

Doctor leaflet, Art50-DL-March, 2012-01, p.1-5.

Dubey R, Vobalaboina V, Dhall V, Gandhi R, Padhi BK, Ramana EA, et al. Diacerein pharmaceutical formulations. Patent no. WO 2009048940 A2. 2009.
Elena PM, Newman FL, Gumus G. Quantitative analysis of 2 treatment options for osteoarthritis in adults: Intra-Articular Hyaluronan Products and Diacerein. Am J Pharm Ben. 2009;1(1):29-37.

Enji A, Basma M, Amera M, Olfat S. Evaluation of the effect of diacerein on IL- $1 \beta$ and osteocalcin levels in GCF of chronic periodontitis patients: A non-randomized controlled clinical trial. J Int Dental Med Res.2016;9(2):98-107.

Felisaz N, Boumediene K, Ghayor C, Herrouin JF, Bogdanowicz $\mathrm{P}$, Galera $\mathrm{P}$, et al. Stimulating effect of diacerein on TGF- $\beta 1$ and $\beta 2$ expression in articular chondrocytes cultured with and without interleukin-1. Osteoarthritis Cartilage. 1999;7(3):25567.

Fidelix TS, Macedo CR, Maxwell LJ, Fernandes MTV. Diacerein for osteoarthritis. Cochrane Database Syst Rev. 2014;1-69.

Flood J. The role of Acetaminophen in the treatment of osteoarthritis. Am J Manag Care. 2010;16:48-54.

Frohnwieser BS, Kaltenegger H, Weigl L, Mann A, Kullicha W, Leithner A, Lohberger B. Pharmacological treatment with diacerein combined with mechanical stimulation affects the expression of growth factors in human chondrocytes. Biochem Biophys Rep. 2017;11:154-60.

Frohnwiesery BS, Weigl L, Kullich W, Lohberger B. The disease modifying osteoarthritis drug diacerein is able to antagonize pro inflammatory state of chondrocytes under mild mechanical stimuli. Osteoarthritis Cartilage. 2014;22(7):1044-52.

Gupta N, Datta S. Efficacy and safety of diacerein and diclofenac in knee osteoarthritis in Indian patients- A prospective randomized open label study. J Biomed Sci. 2012;1(1):1-14.

Gwee AK, Collins SM, Read NW, Rajnakova A, Deng Y, Graham JC, et al. Increased rectal mucosal expression of interleukin $1 \beta$ in recently acquired post-infectious irritable bowel syndrome. Inflammat Motility. 2003;52(4):523-26.

Jatwa R, Kar A. Anti-inflammatory and anti-peroxidative roles of diacerein are possibly mediated through an alteration in thyroid functions in animal model of inflammation. Fundam Clin Pharmacol. 2009;23(4):465-71. 
Kongtharvonskul J, Anothaisintawee T, Mcevoy M, Attia J, Woratanarat P, Thakkinstian A. Efficacy and safety of glucosamine, diacerein, and NSAIDs in osteoarthritis knee: A systematic review and network meta-analysis. Euro J Med Res. 2015;20(1):1-11.

Kruse R, Essen GB, Fossum C, Jensen WM. Blood concentrations of the cytokines IL-1beta, IL-6, IL-10, TNF-alpha and IFNgamma during experimentally induced swine dysentery. Acta Vet Scand. 2008;50:1-7.

Kumar KK, Sasikanth K, Sabareesh M, Dorababu N. Formulation and evaluation of diacerein cream. Asian J Pharm Clin Res.2011;4(2):93-98.

Leeb BF. Clinical efficacy and safety of diacerein in osteoarthritis - a review. Osteoarthritis. 2010;5(1):23-29.

Lohberger B, Leithner A, Stuendl N, Kaltenegger H, Kullich W, Steinecker-Frohnwieser B. Diacerein retards cell growth of chondrosarcoma cells at the G2/M cell cycle checkpoint via cyclin B1/CDK1 and CDK2 downregulation. BMC Cancer. 2015;15:1-11.

Louchahi KP, Nicolas O, Petitjean MT. Study of the pharmacokinetic of ART 50 (diacetylrheine) as a single oral dose of $50 \mathrm{mg}$ fasting and with food, followed by repeated administration of $50 \mathrm{mg}$ B.D. in adult volunteers without overt disease. 1991;1-98.

Magnard O, Louchahi K, Tod M, Petitjean O, Molinier P, Berdah L, Perret G. Pharmacokinetics of diacerein in patients with liver cirrhosis. Biopharm Drug Dispos. 1993;14(5):401-08.

Mahajan A, Singh K, Tandon VR., Kumar S, Kumar H. Diacerein: A new symptomatic slow acting drug for osteoarthritis. JK Sci. 2006;8(3):173-75.

Mandawgade SD, Kulkarni S, Pal A, Srivastava S, Padhi BK, Raghuvanshi RS. Development and parmacokinetic evaluation of new oral formulations of diacerein. Curr Drug Deliv. 2016;13(1):83-89.

Medhi B, Singh PK, Prakash A, Sen R, Wadhwa S. Diacerein: A new disease modulating agent in osteoarthritis. Int J Pharm Med Res. 2007;18:48-52.

Mohan GC, Zhang H, Bao L, Many B, Chan LS. Diacerein inhibits the pro-atherogenic \& proinflammatory effects of IL-1 on human keratinocytes \& endothelial cells. PLOS One. 2017;12(3):1-20.
Moldovan F, Pelletier JP, Jolicoeur FC, Cloutier JM, Pelletier JM. Diacerhein and rhein reduce the ICE-induced IL-1 and IL18 activation in human osteoarthritic cartilage. J Osteoarth Res Society Int. 2000;8(3):186-96.

Nakhat P, Mandaogade P, Jain GK, Talwar M. Self-emulsifying pharmaceutical compositions of rhein or diacerein. Patent No. US 20150164851 A1. 2015.

Napoli D. Diacerein for use in treating psoriasis. Patent No. EP 1248608 B1. 2003.

Osman WA, Elmessiry SAEM, Shaker OG, Zaki IM, Wissa MY, Amer MS, Shamaa AA.Comparative study of the effect of diacerein and diclofenac sodium and their combination in osteoarthritis model induced by monoiodoacetate in albino rats. Res J Pharm Bio Chem Sci. 2015;6(3):1079-89.

Panova E, Jones G. Benefit-risk assessment of Diacerein in the treatment of osteoarthritis. Drug Saf. 2015;38(3):245-52.

Parekh KK, Paun JS, Soniwala MM. Formulation and Evaluation of nanosuspension to improve solubility and dissolution of diacerein. Int J Pharm Sci Res. 2017;8(4):1643-53.

Pavelka K, Bruyere O, Cooper C, Kanis JA, Leeb BF, Maheu E, Martel-Pelletier J, Monfort J, Pelletier JP, Rizzoli R, Reginster JY. Diacerein: benefits, risks and place in the management of osteoarthritis. An opinion-based report from the ESCEO. Drugs Aging. 2016;33(2):75-85.

Pelletier JM, Pelletier JP. Effects of diacerein at the molecular level in the osteoarthritis disease process. Ther Adv Musculoskel Dis. 2010;2(2):95-104.

Pelletier JP, Lajeunesse D, Reboul P, Mineau F, Fernandes JC, Sabouret P, Martel-Pelletier J. Diacerein reduces the excess synthesis of bone remodeling factors by human osteoblast cells from osteoarthritic subchondral bone. J Rheumatol. 2001;28(4):814-24.

Pelletier JP, Mineau F, Fernandes JC, Duval N, Martel-Pelletier J. Diacerhein and rhein reduce the interleukin-1 beta stimulated inducible nitric oxide synthesis level and activity while stimulating cyclooxygenase-2 synthesis in human osteoarthritic chondrocytes. J Rheumatol. 1998;25(12):2417-24.

Pelletier JP, Yaron M, Haraoui B, Cohen P, Nahir MA, Choquette D, et al. Efficacy and safety of Diacerein in osteoarthritis of the knee. Arthritis Rheumatism. 2000;43(10):2339-48. 
Petrosino S, Ahmad A, Marcolongo G, Esposito E, Allara M, Verde $\mathrm{R}$, et al. Diacerein is a potent and selective inhibitor of palmitoylethanolamide inactivation with analgesic activity in a rat model of acute inflammatory pain. Pharmacol Res. 2014;91:9-14.

Ramos-Zavala MG, Gonzalez-Ortiz M, Martinez-Abundis E, Robles-Cervantes JA, Gonzalez-Lopez R, Santiago-Hernandez NJ. Effect of diacerein on insulin secretion and metabolic control in drug-naïve patients with type 2 diabetes. Emerging Treatments Tech. 2011;34:1591-94.

Rao J, Chauhan K, Mahadik KR, Kadam SS. A stabilityindicating high performance liquid chromatographic method for the determination of diacerein in capsules. Ind J Pharm Sci. 2009;71(1):24-29.

Rintelen B, Neumann K, Leeb BF. A meta-analysis of controlled clinical studies with diacerein in the treatment of osteoarthritis. Arch Intern Med. 2006;166(17):1899-906.

Shafshak TS, Shaheen EM, Hussein N, Hafez AA. The efficacy of diacerein with and without diclofenac sodium on knee pain severity and walking time in patients with knee osteoarthritis. Int J Sci Res. 2012;3(12):1685-88.

Tanamas SK, Wijethilake P, Wluka, AE, Davies-Tuck ML, Urquhart DM, Wang Y, et al. Sex hormones and structural changes in osteoarthritis: A systematic review. Maturitas. 2011;69(2):141-561.

Torina AG, Reichert K, Lima F, de Souza Vilarinho KA, de Oliveira PPM, do Carmo HRP, de Carvalho DD, Saad MJA, Sposito AC, Petrucc O. Diacerein improves left ventricular remodeling and cardiac function by reducing the inflammatory response after myocardial infarction. PLOS One. 2015;10(3):113.
Villar MM, Martinez-Abundis E, Preciado-Marquez RO, Gonzalez-Ortiz M. Effect of diacerein as an add-on to metformin in patients with type 2 diabetes mellitus and inadequate glycemic control. Arch Endocrinol Metab. 2017;61(2):188-192.

Wally V, Kitzmueller S, Lagler F, Moder A, Hitzl W, Wolkersdorfer M, et al. Topical diacerein for epidermolysis bullosa: A randomized controlled pilot study. Orphanet J Rare Dis. 2013;8:2-3.

World Health Organization. WHO Pharmaceuticals Newsletter No. 2, 2014. 2-29 p.

Woolf AD, Pfleger B. Burden of major musculoskeletal conditions. Bull WHO. 2003;81(9):646-56.

Yan XZ, Xia W, Yue W, Peng C, Rahman K, Zhang H. Rhein: A review of pharmacological activities. Evid Based Complement Alternat Med. 2015;1-10.

Yaron M, Shirazi I, Yaron I. Anti-interleukin-1 effects of diacerein and rhein in human osteoarthritic synovial tissue and cartilage cultures. Osteoarthritis Cartilage. 1999;7(3):272-80.

Zaki BM, Mahmoud EA, Aly AA. Diacerein: A potential therapeutic drug for the management of experimental periodontitis in rats. Electronic Physician. 2015;7(5):1290-95.

Zaki RM, Ali AA, El Menshawi SF, Bary AA. Effect of binary and ternary solid dispersions prepared by fusion method on the dissolution of poorly water soluble diacerein. Int J Drug Deliv. 2013;5:99-109.

Received for publication on $02^{\text {nd }}$ September 2017 Accepted for publication on $07^{\text {th }}$ March 2018 